\title{
Therapeutic effects of aerial parts of Smyrnium cordifolium ethanolic extract on ethylene glycol-induced kidney calculi in rats
}

\author{
Zohreh Dovodizadeh ${ }^{1}$, Leila Rouhi ${ }^{1 *}$, Shahrzad Azizi ${ }^{2}$
}

1. Department of Animal Physiology, Faculty of Basic Sciences, Shahrekord Branch, Islamic Azad University, Shahrekord, Iran

2. Department of Pathobiology, Faculty of Veterinary Medicine, Shahid Bahonar University of Kerman, Kerman, Iran

*Corresponding author:Tel: +98 9126043305 Fax: +98

Address: Department of Animal Physiology, Faculty of Basic Sciences, Shahrekord Branch, Islamic Azad

University, Shahrekord, Iran

E-mail: Lrouhi59@gmail.com

Received; 2017/07/5 revised; 2017/11/10 accepted; 2018/04/25

\section{Abstract}

Introduction: In this study, the effects of the ethanolic extract of aerial parts (stem and leaves) of Smyrnium cordifolium (S. cordifolium) Boiss on the ethylene glycol(EG)-induced kidney calculi in rats was investigated.

Materials and methods: Thirty-six male Wistar albino rats were randomly divided in 6 groups. Group I (normal control), Groups II (control of EG) to VI received EG 1\% v/v in water for 28 days. Animals in Groups III and IV (preventive groups) received ethanolic extract of stem and leaves of $S$. cordifolium in $200 \mathrm{mg} / \mathrm{kg}$ and $400 \mathrm{mg} / \mathrm{kg}$ orally in water for 28 days, respectively. Groups V and VI (treatment groups) received extract in $200 \mathrm{mg} / \mathrm{kg}$ and $400 \mathrm{mg} / \mathrm{kg}$ orally in water from 15 th to 28 th day, respectively.

Results: Results showed that the level of urine oxalate, blood urea and creatinine in EG group vs. normal control significantly increased $(\mathrm{P}<0.001)$. Extract did not show significant effect on urinary oxalate, urine volume and other blood biochemical parameters in the treatment groups (V and VI). Provision of extract resulted in significantly lower levels of urine oxalate and higher level of volume, serum creatinine and blood urea in III and IV groups as compared with Group II $(\mathrm{P}<0.05)$.

Conclusion: These observations enable us to conclude that the ethanolic extract of aerial parts of S. cordifolium Boiss is effective against EG induced urinary calculi in rats.

Keywords: Kidney stone, Ethyl glycol-induced kidney calculi, Smyrnium cordifolium Boiss

\section{Introduction}

Urinary calculi are the third prevalent disorder in the urinary system, which may cause obstruction, hydronephrosis, infection, and hemorrhage in the urinary tract system (1). The risk of developing urinary calculi in adults appears to be higher in the western hemisphere $(5-9 \%$ in Europe, $12 \%$ in Canada, and $13-15 \%$ in the USA) than in the eastern hemisphere (1-5\%) (2). However, approximately $75 \%$ of stones are primarily calcium oxalate (3). Extracorporeal shock wave lithotripsy, percutaneous lithotomy, transureteral lithotripsy, and even laparoscopy are widely used to remove the calculi. However, using these invasive procedures is not cost effective and may also lead to severe complications. Thus, more efforts are needed to better assess medical therapy and to develop new agents that can be used

Copyright (C) 2018 Journal of Basic Research in Medical Science. This is an open access article distributed under the terms of the Creative Commons Attribution 4.0 International License (https://creativecommons.org/licenses/by-nc/4.0/) which permits copy and redistribute the material, in any medium or format, provided the original work is properly cited. 
either alone or combined to prevent stone formation more efficiently with fewer side-effects. Therefore, it is worthwhile to replace these conventional treatments with medicinal plants or phytotherapy. Medical plants are used worldwide and there is an increasing interest in research in this area to provide a scientific basis for their beneficial effects (4-9).

Ethylene glycol (EG) has two toxic metabolites; glycolic acid, which is responsible for the acidosis, and oxalic acid (10). The toxic effects increase free radical production and lipid peroxidation.

Smyrnium cordifolium is one of the range plants in native pasture in mid-south of Iran especially in Kohgiloyeh and Bovir Ahmad province (southwest of Iran). Genus Smyrnium belongs to Umbelliferae family and is used by people as an herbal medicine in treatments for internal organ edema, especially in bladder and kidney problems. The roots, stems and leaves contain strongly odored phenolic essence. Stem and leaves of $S$. cordifolium are used traditionally for treatment of kidney stones in Iran (11). In another study reported that essential oils obtained from stem leaves, roots and fruit of $S$. cordifolium have antibacterial effects, which they claim are due to the large amounts of sesquiterpene hydrocarbons such as curzerene, curzerenone and germacrone (12). $S$. cordifolium is a native of Iran and eaten as a green by some people in west part of Iran. It is often used internally for bladder and kidney swelling (11).

Though, it is used as a folk medicine for treatment of renal calculi, its effectiveness and mechanism as anti-urolithiatic agent is still unknown. We have described in this study preventive and treatment effects of renal calculi.

\section{Materials and methods}

Thirty-six male Wistar albino rat (250-350 g) were randomly divided into six equal groups. Group I received water and served as normal control. Group II to VI received EG $1 \% \mathrm{v} / \mathrm{v}$ in water for 28 days. Group II served as EG control group. Animals in Group III and IV (preventive groups) received ethanolic extract of stem and leave of $S$. cordifolium in $200 \mathrm{mg} / \mathrm{kg}$ and $400 \mathrm{mg} / \mathrm{kg}$ orally in water for 28 days, respectively. Group V and VI (treatment groups) did not receive extract for first 14 days. These groups received extract in 200 $\mathrm{mg} / \mathrm{kg}$ and $400 \mathrm{mg} / \mathrm{kg}$ orally in water from 15th to 28th day, respectively (13).

Twenty-four hr. urine specimens were collected on day 0 and 28 of the study by keeping each rat in separate metabolic cage. Urine volume was measured and kept under refrigeration $\left(2-8{ }^{\circ} \mathrm{C}\right)$. Urinary oxalate was measured by oxalate kit by spectrophotometer. Blood samples were collected from heart on day 28 and serological parameters for renal functions were measured.

The animals were sacrificed soon after blood collection under the continued effect of anesthesia. Both kidneys were removed and were fixed in $10 \%$ neutral buffered formalin for at least 48 hours. Then, tissue samples were embedded in the paraffin block. Sections in $5 \mu \mathrm{m}$ thickness were stained with hematoxylin-eosin and evaluated under optical light microscope.

\section{Statistical analysis}

One-way ANOVA and post-hoc Tukey tests were used for analysis of serum and urine parameters. The non-parametric Kruskal-Wallis test and Mann-Whitney $U$ test were used for comparison of $\mathrm{CaOx}$ deposites. $\mathrm{P}$ values of less than 0.05 were considered statistically significant. Data were expressed as mean \pm standard error (SEM).

\section{Results}

Urinary parameters: There was no statistically significant difference in urinary volume and oxalate in all the groups on day 0 . Urinary oxalate was significantly increased after EG administration. Urine volume was significantly decreased by EG in group II 
$(\mathrm{P}<0.05)$. Urine volume in the preventive groups was increased but not significant and in treatment groups was significantly increased (Table 1, $\mathrm{P}<0.05$ ). A significant decrease in the urinary excretion of oxalate was observed in both the preventive groups (III and IV; $\mathrm{P}<0.01$ ), but in the treatment groups (V and VI), not significant change was present in compared to the EG group (Table 2).

\section{Biochemical parameters: EG} administration increased the values of blood urea and serum creatinine significantly as compared to the normal control group. $S$. cordifolium extract showed the significant improvement in the renal parameters in the preventive groups $(\mathrm{P}<0.05)$. Renal parameters were nonsignificantly improved in the treatment groups (Table 3).
Histopathological evaluation: The normal control group and only received extracts groups had kidney with normal histology (Figure 1). EG treated rats, the epithelium of renal tubules revealed vacuolar degeneration and necrosis and glomeruli had become atrophy. Hyaline casts were observed in the most tubular lumen (Figure 2). In the preventive groups that received 200 and $400 \mathrm{mg} / \mathrm{kg}$ of $S$. cordifolium extract for 28 days, renal lesions including degenerative changes and necrosis of the epithelial tubules reduced, and less hyaline casts were present in their lumens (Figure 3). No remarkable difference was observed between two treated groups. Also, induced injuries by EG decreased in treated groups with 200 and $400 \mathrm{mg} / \mathrm{kg}$ of $S$. cordifolium extract (Figure 4). No remarkable difference was observed between concentrations.

Table 1. Effect of ethanolic extract of aerial parts of Smyrnium cordifolium Boiss on the urine volume (ml/24h) in different groups of rats.

\begin{tabular}{lllllll}
\hline & Group I & Group II & Group III & Group IV & Group V & Group VI \\
\hline 0th day & $4.4 \pm 0.05$ & $4.1 \pm 0.05$ & $4.1 \pm 0.05$ & $4.3 \pm 0.05$ & $4 \pm 0.05$ & $3.9 \pm 0.05$ \\
28th day & $4.3 \pm 0.05$ & $2.5 \pm 0.05^{*}$ & $4.2 \pm 0.05^{* *}$ & $4.6 \pm 0.05^{* *}$ & $2.7 \pm 0.05^{\#}$ & $2.9 \pm 0.05^{\#}$ \\
\hline
\end{tabular}

All values are expressed as mean \pm SEM. $\mathrm{n}=6$ for all groups. $* \mathrm{P}<0.01$ as compared to group $\mathrm{I}, * * \mathrm{P}<0.05$ as compared to group II, \#P<0.01 as compared to group I, III and IV.

Table 2. Effect of ethanolic extract of aerial parts of Smyrnium cordifolium Boiss on urine oxalate (mmol/24h) in different groups of rats.

\begin{tabular}{lllllll}
\hline & Group I & Group II & Group III & Group IV & Group V & Group VI \\
\hline 0th day & $0.4 \pm 0.05$ & $0.41 \pm 0.05$ & $0.38 \pm 0.05$ & $0.52 \pm 0.05$ & $0 \pm 47.05$ & $0.39 \pm 0.05$ \\
28th & $0.37 \pm 0.05$ & $1.5 \pm 0.05^{*}$ & $0.92 \pm 0.05^{* *}$ & $0.6 \pm 0.05^{* *}$ & $1.2 \pm 0.05$ & $1 \pm 0.05$
\end{tabular}

day

All values are expressed as mean \pm SEM. $\mathrm{n}=6$ for all groups. $* \mathrm{P}<0.01$ as compared to group $\mathrm{I}, * * \mathrm{P}<0.01$ as compared to group II.

Table 3. Effect of ethanolic extract of aerial parts of Smyrnium cordifolium Boiss on biochemical parameters in different groups of rats.

\begin{tabular}{lcccccc}
\hline & Group I & Group II & Group III & Group IV & Group V & Group VI \\
\hline Blood Urea $(\mathrm{mg} / \mathrm{dl})$ & $35.4 \pm 0.05$ & $125.41 \pm 0.05^{*}$ & $54.38 \pm 0.05^{* *}$ & $38.52 \pm 0.05^{* *}$ & $65 \pm 47.05$ & $83.39 \pm 0.05$ \\
Creatinine $(\mathrm{mg} / \mathrm{dl})$ & $0.6 \pm 0.05$ & $2.5 \pm 0.05^{*}$ & $0.82 \pm 0.05^{* *}$ & $0.7 \pm 0.05^{* *}$ & $1.92 \pm 0.05$ & $1.81 \pm 0.05$ \\
\hline
\end{tabular}

All values are expressed as mean \pm SEM. $\mathrm{n}=6$ for all groups. $* \mathrm{P}<0.01$ as compared to group $\mathrm{I}$, $* * \mathrm{P}<0.01$ as compared to group II. 


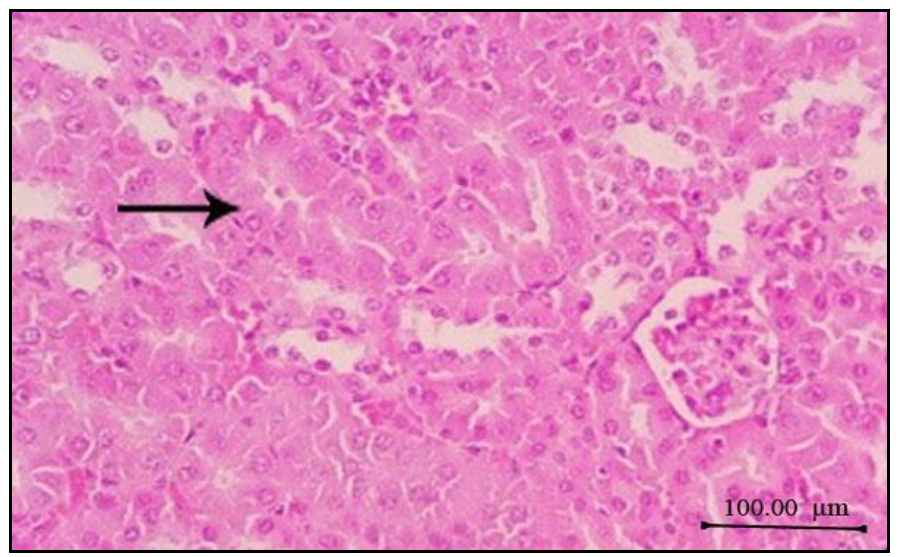

Figure 1. Normal histology of kidney with light eosinophilic cytoplasm (arrow) and vesicular nuclei in the Normal control group of the rats under study.
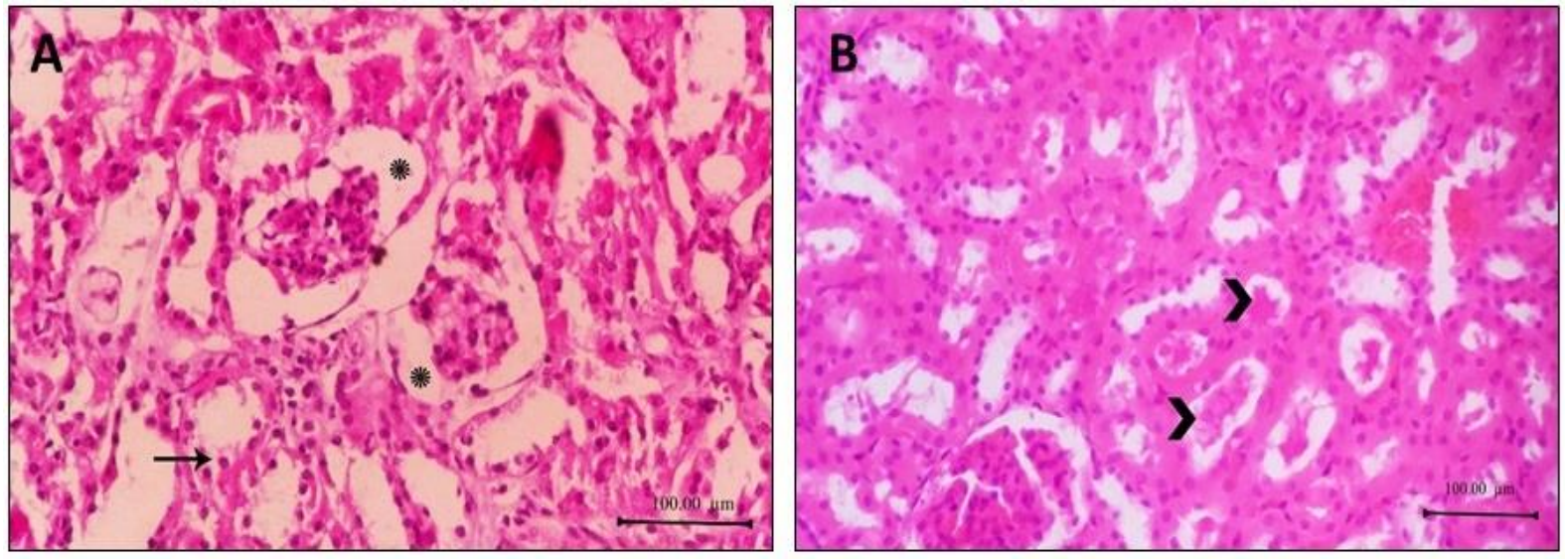

Figure 2. Histopathological status of the kidney in treatment groups of the rats under study. A) Ethylene glycol group; severe degeneration and necrosis (arrow) as well as glomeruli atrophy and dilation of urinary space (asterisks). B) Presence of hyaline casts (arrowheads) in the most of tubules (HE, Bar= $100 \mu \mathrm{m}$ ).

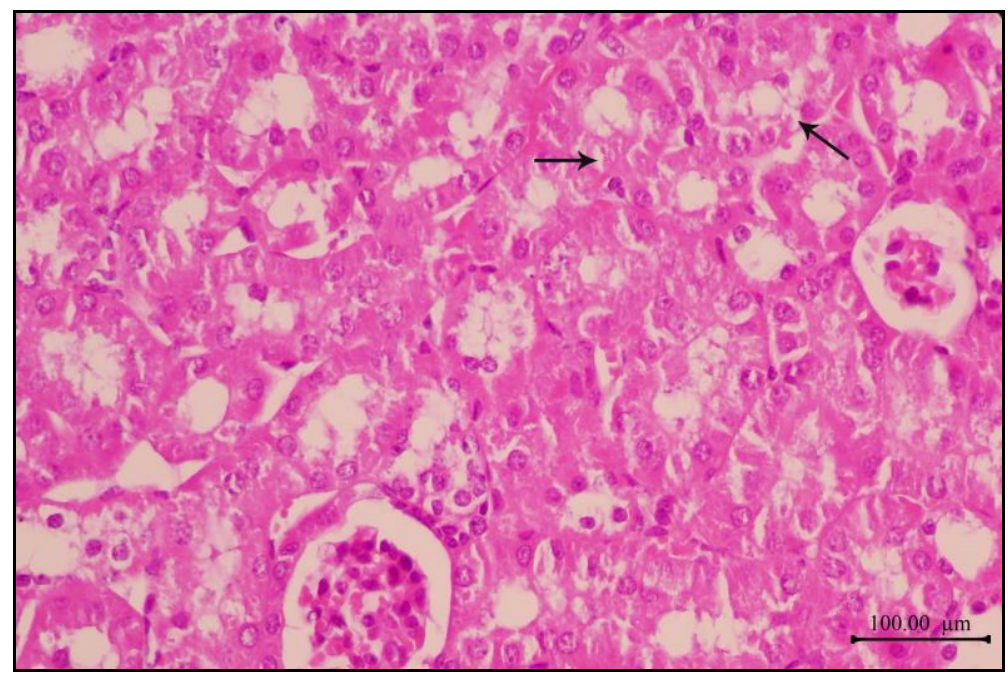

Figure 3. Histopathological status of the kidney in the Preventive group of the rats under study. Reduction of vacuolar degeneration (arrows), necrosis and hyaline casts in the tubules after reception of Smyrnium cordifolium Boiss extract (HE, Bar= $100 \mu \mathrm{m})$. 


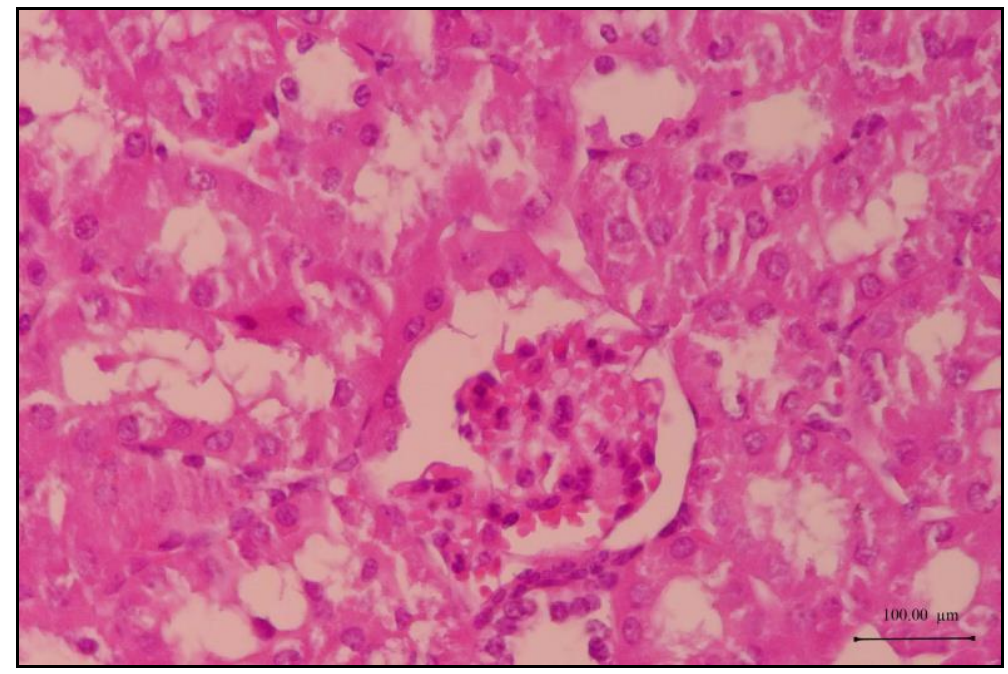

Figure 4. Histopathological status of the kidney in the Treatment group of rats. Reduction of vacuolar degeneration, necrosis and hyaline casts in the tubules due to Smyrnium cordifolium Boiss extract (HE, Bar= $100 \mu \mathrm{m})$.

\section{Discussion}

Our data demonstrated that aqueous extract of stem and leaves of $S$. cordifolium had a preventive effect on kidney calculi formation in the kidney of rats. The aqueous extract also decreased the number of $\mathrm{CaOx}$ calculi in the treated group and therefore, demonstrates a therapeutic effect, albeit trivial, on the disruption of $\mathrm{CaOx}$ calculi formed in the kidney due to EG consumption. The $S$. cordifolium extract with the dose of 400 $\mathrm{mg} / \mathrm{kg}$ had a significant preventive effect on the formation of $\mathrm{CaOx}$ kidney calculus. To our knowledge, this is the first report on the effect of aqueous extract of the $S$. cordifolium on the prevention and treatment of $\mathrm{CaOx}$ calculi.

Calcium oxalate crystals in the nephrons cause damages of the epithelial cells, and consequently produce free radicals and some components inducing heterogenous crystal nucleation that result in aggregation of crystals (14). It has been reported that $\mathrm{CaOx}$ calculi similar to the struvite calculi may have a bacterial origin (15). Khan ahmadi et al (2015) studied the antioxidant and antibacterial activities of soluble compounds in extracts from the aerial parts of fresh $S$. cordifolium Boiss. They reported that the extracts of this plant contain antioxidant and antibacterial activities (16).

In urinary calculi, the glomerular filtration rate (GFR) decreases, due to the obstruction of the urine outflow by urinary stones. Therefore, the waste products particularly nitrogenous substances such as urea, creatinine and BUN accumulate in blood. EG increases blood urea and creatinine levels significantly due to impairment in renal function. EG has two toxic metabolites; glycolic acid, which is responsible for the acidosis, and oxalic acid, which precipitates as calcium oxalate monohydrate (COM) in the kidney, and causes proximal tubular cell necrosis. The toxic effects increase free radical production and lipid peroxidation (17). EG is metabolized into glycolaldehyde acid, glycolic acid, glyoxylic acid, and oxalic acid. The formed oxalic acid is largely excreted in urine as oxalate. It is precipitated by calcium ions to form $\mathrm{CaOx}$ crystals (18).

In the present study, $S$. cordifolium extract had significantly decreased degenerative changes and necrosis of the proximal tubules, and also levels of creatinine and urea in the different experimental groups. 
Diuretic action is also needed to increase the amount of fluid going through the kidneys and flush out the deposits. Increasing urine volume reduces the saturation of the salts and prevents the precipitation of the crystals at physiological $\mathrm{pH}$ (19). S. cordifolium Boiss is a spring plant which was traditionally used as diuretic plant and expellant for kidney stones (20).

In the present study, the histopathological findings supported the data obtained from biochemical and urine analysis. However, EG treated group which showed swelling and vacuolar degeneration of the tubular epithelium as well as hyaline cast in the tubular lumen that indicate excretion of protein through the glomeruli but those from treated rats were apparently of near normal architecture with very few crystals and deposits. The effect was more pronounced in higher dose group.

Calcium oxalate crystals and high levels of oxalate in the nephrons can damage the epithelial cells, and consequently, the cells may produce some products as well as free radicals, inducing heterogeneous crystal nucleation and cause aggregation of crystals (13).

The exact mechanisms through which $S$. cordifolium extract affects $\mathrm{CaOx}$ calculi are still under debate. It is speculated that $S$. cordifolium extract could prevent the formation of $\mathrm{CaOx}$ calculi and their disaggregation through its antiinflammatory and antioxidant mechanisms. Furthermore, extract may interfere with the process of epithelial cell damage induced by crystals. Several studies have reported

\section{References}

1. Stoller ML, Bolton DM. Urinary stone diseases. In: Tanagho EA, McAninch JW, eds. Smith's general urology. $15^{\text {th }}$ ed. Ohio: McGraw-Hill Medical. 2004, p:291-321.

2. Lopez M, Hoppe B. History, epidemiology and regional diversities of urolithiasis. Pediatr Nephrol. that flavonoids have anti-inflammatory and antioxidant effects (21). It can be speculated that of the role of the $S$. cordifolium extract in preventing formation of $\mathrm{CaOx}$ calculi and disruption of them, as seen in the present study, is in part due to the anti-inflammatory and antioxidant effects of the different compounds of extract.

\section{Conclusion}

The present study was conducted to evaluate the antiurolithiatic activity of ethanolic extract of aerial parts of $S$. cordifolium. We could find that the extract of stem and leaves of $S$. cordifolium significantly decreased the number and size of $\mathrm{CaOx}$ deposits in different parts of the renal tubules. The antiurolithiatic activity of the plant may probably be due to synergism of diuretic activity, crystallization inhibition and improved renal function along with antioxidant activity. It also seems that the preventive properties of ethanolic extract are more effective than its treatment effect. Further studies on larger animal models and on human are required to draw final conclusions.

\section{Acknowledgment}

This study was supported by Islamic Azad University of shahrekord branch.

\section{Conflict of interests}

There is no conflict of interest.
2010;25(1):49-59.

doi: 10.1007/s00467-008-0960-5.

3. Reynolds TM. Chemical pathology clinical investigation and management of nephrolithiasis. J Clin Pathol. 2005; 58(2): 134-140. 10.1136/jcp.2004.019588. 
4. Hadjzadeh MA, Khoei A, Hadjzadeh Z, Parizady MC. Ethanolic extract of Nigella sativa L seeds on ethylenecglycol-induced kidney calculi in rats. Urol J. 2007;4(2):86-90.

5. Christina AJ, Packia Lakshmi M, Nagarajan M, Kurian S. Modulatory effect of Cyclea peltata Lam. on stone formation induced by EG treatment in rats. Methods Find Exp Clin Pharmacol. 2002;24(2):77-9. doi: 10.1358/mf.2002.24.2.677130.

6. Hadjzadeh MA, Mohammadian N, Rahmani Z, Rassouli FB. Effect of thymoquinone on ethylene glycolinduced kidney calculi in rats. Urol J. 2008;5(3):149-55.

7. Atmani F, Slimani Y, Mimouni M, Aziz M, Hacht B, Ziyyat A. Effect of aqueous extract from Herniaria hirsuta L. on experimentally nephrolithiasic rats. J Ethnopharmacol. 2004;95(1):8793. doi: 10.1016/j.jep.2004.06.028.

8. Grases F, Ramis M, Costa-Bauza A, March JG. Effect of Herniaria hirsuta and Agropyron repens on calcium oxalate urolithiasis risk in rats. $\mathrm{J}$ Ethnopharmacol. 1995;45(3):211-4. doi: 10.1016/0378-8741(94)01218-O.

9. Laroubi A, Touhami M, Farouk L, Zrara I, Aboufatima R, Benharref A, Chait A. Prophylaxis effect of Trigonella foenum graecum L. seeds on renal stone formation in rats. Phytother Res. 2007;21(10):921-5. doi: 10.1002/ptr.2190.

10. Welsch F. The mechanism of ethylene glycol ether reproductive and developmental toxicity and evidence for adverse effects in humans. Toxicol Lett. 2005;28;156(1):13-28. doi: 10.1016/j.toxlet.2003.08.010.

11. Mehrabi Y, Mehrabi N. Determination of feed nutritive value of Smyrnium cordifolium Boiss in animal nutrition. Middle-East J Sci Res. 2011;10(5):569-663.

12. Amiri H, Khavari-Nejad R, Ramezan A, Masoud SH, Chalabian F, Rustaiyan A. Composition and antimicrobial activity of the essential oil from stems, leaves, fruits and roots of Smyrnium cordifolium boiss. from Iran. J Essent Oil Res. 2006;18(5):574-7. doi: 10.1080/10412905.2006.9699172

13. Mandavia DR1, Patel MK, Patel JC, Anovadiya AP, Baxi SN, Tripathi CR. Anti-urolithiatic effect of ethanolic extract of Pedalium murex linn. Fruits on ethylene glycol-induced renal calculi. Urol J. 2013; 10(3): 946-52.

14. Khan SR, Thamilselvan S. Nephrolithiasis: a consequence of renal epithelial cell exposure to oxalate and calcium oxalate crystals. Mol Urol. 2000;4(4):305-12.

15. Kramer G, Klingler HC, Steiner GE. Role of bacteria in the development of kidney stones. Curr Opin Urol. 2000;10(1):35-8.

16. Khan ahmadi M, Rezazadeh SH, Taran M. In vitro antimicrobial and antioxidant properties of Smyrnium cordifolium Boiss. (Umbelliferae) extract. Asian J Plant Sci. 2010; 9(2): 99-103. doi: 10.3923/ajps.2010.99.103.

17. Thamilselvan S, Hackett RL, Khan SR. Lipid peroxidation in ethylene glycol induced hyperoxaluria and calcium oxalate nephrolithiasis. J Urol. 1997;157(3):1059-63.

18. Al-Attar AM. Antilithiatic influence of spirulina on ethylene glycol-induced nephrolithiasis in male rats. Am J Biochem Biotechnol. 2010;6(1):25-31. doi: 10.3844/ajbbsp.2010.25.31.

19. Pareta SK, Patra KC, Mazumder PM, Sasmal D. Establishing the principle of herbal therapy for antiurolithiatic activity: a review. J Pharmacol Toxicol. 2011;6(3):321-332. doi: 10.3923/jpt.2011.321.332.

20. Ahvazi M, Khalighi-Sigaroodi F, Charkhchiyan MM, Mojab F, Mozaffarian V, Zakeri H. Introduction of medicinal plants species with the most traditional usage in alamut region. Iran J Pharm Res. 2012;11(1):185-194. 
21. Nair MP, Mahajan S, Reynolds JL. The flavonoid quercetin inhibits proinflammatory cytokine (tumor necrosis factor alpha) gene expression in normal peripheral blood mononuclear cells via modulation of the NF-kappa beta system. Clin Vaccine Immunol. 2006;13(3):319-28. doi: 10.1128/CVI.13.3.319-328.2006. 